\title{
Remodeling of the left heart in patients with rheumatic mitral valve disease after mitral valve replacement with preservation of subvalvular structures
}

Dinara B. Toktosunova, Murat K. Djundubaev, Elmira D. Seytahunova, Irina A. Akhmedova

Scientific Research Institute of Heart Surgery and Organ Transplantation of the Ministry of Health of the Kyrgyz Republic, Bishkek, Kyrgyzstan

\begin{abstract}
Objectives: to evaluate the advantage of preserving the subvalvular structures of the mitral valve from both leaflets compared with the preservation of the subvalvular structures only from the posterior valve during mitral valve replacement surgery (MVR).

Methods: A retrospective analysis of case histories of 41 patients with isolated rheumatic lesions of the mitral valve who underwent MVR, which were divided into 2 groups: with complete preservation of subvalvular structures $(n=$ 24 ) and preservation of only the posterior leaflet $(n=17)$, was performed.

Results: In the group with complete preservation of the chordal-papillary apparatus, there was a significant decrease in the end-systolic volume $(p<0.05)$ and a slight increase in the ejection fraction of the left ventricle in the immediate postoperative period compared with the group with the preservation of the chordal-papillary apparatus only from the posterior cusp, where end-systolic volume decreased slightly $(p>0.05)$ and the ejection fraction of the left ventricle remained at the same levels.

Conclusion: Our preliminary results of the study indicate better remodeling and optimization of the geometry of the left ventricle when assessing the closest postoperative parameters in a group of patients with preservation of chordo-papillary structures of both leaflets, both the anterior and the posterior leaflets.
\end{abstract}

Key words: mitral valve, mitral valve replacement, subvalvular structures, remodeling of the left ventricle

(Heart Vessels Transplant 2020; 4; 40-4. doi: 10.24969/hvt.2020.204)

\section{Introduction}

Currently, in developing countries there is no tendency to a constant decrease in the number of patients with rheumatic lesions of the mitral valve, which are presented in the form of pronounced morphological changes requiring replacement of the affected valve (1-3). And in this group of patients, preservation of the subvalvular apparatus is an important concept, the purpose of which is to restore and preserve the native geometric shape of the left ventricle, to improve contractility and remodeling of the left heart (3-4).The report of conflicting long-term results when replacing the mitral valve with complete excision of annulopapillary continuity appeared in 1964 (5). Subsequently, many studies were carried out showing the advantage of retaining the posterior leaflet with subvalvular structures with removal of the anterior leaflet with subvalvular apparatus over complete interruption of annulo-papillary continuity [6). Meanwhile, studies began to be published proving the greater effectiveness of the full conservation of annulo-papillary continuity when subvalvular structures from both the anterior and posterior cusps were preserved, in contrast to the preservation of subvalvular structures only from the posterior cusp when the anterior cusp was excised with subvalvular structures. However, with rheumatic lesions, there are still conflicting opinions, such as the impossibility of implanting the desired prosthesis size while completely retaining the subvalvular structures, the creation of obstruction of the outflow tract of the left ventricle, which requires the development of various methods for maintaining anatomical integrity, and a study with a poor result, in independence of subvalvular structures are preserved or not (7-9). 
The aim of the study was to compare the results of mitral valve replacement surgery (MVR) with complete preservation of subvalvular structures and with preservation of subvalvular structures only of the posterior leaflet.

\section{Methods}

\section{Design of the study and population}

A retrospective analysis of case histories of 41 patients with isolated rheumatic mitral valve disease who underwent MVR at the Science Research Institute of Heart Surgery and Organ Transplantation from March to December 2018 was performed. Of these, 24 patients underwent complete preservation of subvalvular structures (Group 1) and 17 patients only the posterior leaflet was retained (Group 2). Patients with an isolated mitral valve lesion were included, both with a predominance of stenosis and regurgitation, patients with the presence of concomitant cardiac pathologies were excluded. Informed consent was obtained from all patients prior to surgery.

\section{Baseline data}

The data collected included: age, gender, NYHA class of chronic heart failure, aortic clamping time, mechanical ventilation time, presence of inotropic support, and intensive care unit (ICU) stay duration.

\section{Transthoracic echocardiography}

Transthoracic echocardiography (ECHOCG) was performed in all patients, upon admission and before discharge. ECHOCG was performed on a GE Vivid e9 apparatus (GE Medical Systems, USA). The following echocardiographic parameters were included in the analysis: antero-posterior size of the left atrium (LA), end-diastolic dimension of the left ventricle (LVEDD), end-systolic dimension of the left ventricle (LVESD), end-diastolic volume of the left ventricle (LVEDV), end-systolic volume of the left ventricle (LVESV), and left ventricular ejection fraction (LVEF) according to Simpson rule, mitral valve area and pressure gradient. Cardiac chamber measurements were performed using long-axis view and volumes - 4-chamber view using standard recommended technique (10). Mitral valve area, degree of mitral stenosis and regurgitation were assessed according to guidelines $(11,12)$.

\section{Surgical technique}

The operations were performed by different surgeons, the preference for the preservation of both cusps or only the posterior cusp was given by the operating surgeons themselves.
Group 1: in 22 cases, subvalvular structures from the anterior valve are stored on the sites in an anatomical position, and the posterior valve with subvalvular structures is completely preserved, with the removal of chord-free parts of the valves and decalcification in case of calcination of the valves. In 2 patients, due to gross changes in subvalvular structures, chordalpapillary continuity from both muscles was created using PTFE filaments and fixed to the ring in the area of commissures. Of 24 patients in 23 patients, suture annuloplasty of the tricuspid valve was simultaneously performed.

Group 2: a technique for maintaining the rear leaflet removal of the anterior leaflet with a chordal-papillary apparatus was applied. The posterior cusp and subvalvular structures were retained with decalcification in case of calcification of the latter. At the same time, suture annuloplasty of the tricuspid valve was performed in 12 cases.

\section{Statistical analysis}

Comparison of categorical variables between 2 groups was done using Chi-square test, and comparison of continuous variables between 2 groups was done using $t$ test for independent samples. Comparison of continuous variables within 1 group before and after surgery was performed using $t$ test for dependent samples. $\mathrm{P}<0.05$ was accepted as a significant value.

\section{Results}

Both groups did not differ by demographic variables, NYHA class, severity of mitral stenosis or regurgitation, though not significantly in group 2 there were slightly more patients with mitral regurgitation (Table 1).

In Group 1, in $17 \%$ of patients, signs of severe heart failure (NYHA IV) (Table 1), gross fibrosis of the valves in 11 patients, compaction with shortening of the valves in 2 patients, calcification of grade 1 (leaflet edge) in 9 , and calcification of grade 2 (entire leaflet) in 2- $x$ patients were revealed.

In Group 2, NYHA class IV was present initially in $12 \%$ of patients, gross cusp fibrosis was found in 9 patients, compaction with shortened cusps - in 4 patients, calcification of grade 1 - in 3, calcification of grade 2 - in 1 patient.

All patients were implanted with mechanical doubleleaflet artificial valves \#29 in the mitral position. In Group 1, the chordal-papillary apparatus of the anterior and posterior cusp was preserved. In Group 2 , subvalvular structures of only the posterior leaflet were preserved. 


\begin{tabular}{|c|c|c|c|}
\hline Variables & Group $1(n=24)$ & Group $2(n=17)$ & $p$ \\
\hline Age, years & $49.0(14.7)$ & $49.9(12.6)$ & 0.41 \\
\hline $\begin{array}{l}\text { Sex, } \mathrm{n}(\%) \\
\text { Female } \\
\text { Male }\end{array}$ & $\begin{array}{l}19(79) \\
5(21)\end{array}$ & $\begin{array}{l}11(65) \\
6(35)\end{array}$ & 0.30 \\
\hline $\begin{array}{l}\text { Heart failure functional class (NYHA), n(\%) } \\
\text { III } \\
\text { IV }\end{array}$ & $\begin{array}{l}20(83) \\
4(17)\end{array}$ & $\begin{array}{l}15(88) \\
2(12)\end{array}$ & 0.19 \\
\hline $\begin{array}{l}\text { Morphology, } \mathrm{n}(\%) \\
\text { With a predominance of stenosis } \\
\text { With a predominance of regurgitation }\end{array}$ & $\begin{array}{l}12(50) \\
12(50)\end{array}$ & $\begin{array}{l}5(29) \\
12(71)\end{array}$ & 0.18 \\
\hline $\mathrm{MVA}, \mathrm{cm}^{2}$ & $2.24(1.52)$ & $2.54(1.3)$ & 0.25 \\
\hline Pressure gradient, $\mathrm{mmHg}$ & $14.9(7.6)$ & $13.3(7.4)$ & 0.25 \\
\hline Aortic clamping time, $\mathrm{min}$ & $54(12)$ & $63(33)$ & 0.14 \\
\hline Mechanical ventilation time, $\min$ & $540(170)$ & $860(490)$ & 0.009 \\
\hline Inotropic support, n(\%) & $8(33.3)$ & 9 (52.9) & 0.20 \\
\hline
\end{tabular}

\begin{tabular}{|c|c|c|c|}
\hline Variables & At admission & Before discharge & $p$ \\
\hline $\begin{array}{l}\text { LA, mm } \\
\text { Group } 1 \\
\text { Group } 2 \\
\end{array}$ & $\begin{array}{l}49.7(6.5) \\
51.2(10.0) \\
\end{array}$ & $\begin{array}{l}42.5(5.0) \\
44.7(7.1) \\
\end{array}$ & $\begin{array}{l}<0.05 \\
<0.05 \\
\end{array}$ \\
\hline $\begin{array}{l}\text { LV end-diastolic dimension, } \mathrm{mm} \\
\text { Group } 1 \\
\text { Group } 2\end{array}$ & $\begin{array}{l}52.2(8.0) \\
55.8(6.6)\end{array}$ & $\begin{array}{l}50.4(6.0) \\
53.8(5.9)\end{array}$ & $\begin{array}{l}>0.05 \\
>0.05\end{array}$ \\
\hline $\begin{array}{l}\text { LV end-systolic dimension, } \mathrm{mm} \\
\text { Group } 1 \\
\text { Group } 2\end{array}$ & $\begin{array}{l}34.8(6.2) \\
37(8.1)\end{array}$ & $\begin{array}{l}32.8(4.8) \\
36.9(7.2)\end{array}$ & $\begin{array}{l}>0.05 \\
>0.05\end{array}$ \\
\hline $\begin{array}{l}\text { LV end-diastolic volume, } \mathrm{ml} \\
\text { Group } 1 \\
\text { Group } 2\end{array}$ & $\begin{array}{l}105(53.4) \\
131(57.1) \\
\end{array}$ & $\begin{array}{l}95.2(43.7) \\
116(49.6) \\
\end{array}$ & $\begin{array}{l}>0.05 \\
<0.05\end{array}$ \\
\hline $\begin{array}{l}\text { LV end-systolic volume, } \mathrm{ml} \\
\text { Group } 1 \\
\text { Group } 2\end{array}$ & $\begin{array}{l}44.2(21.8) \\
54.5(38.9)\end{array}$ & $\begin{array}{l}37.1(18.1) \\
52(33.8)\end{array}$ & $\begin{array}{l}<0.05 \\
>0.05\end{array}$ \\
\hline $\begin{array}{l}\text { LV EF, \% } \\
\text { Group } 1 \\
\text { Group } 2\end{array}$ & $\begin{array}{l}57.7(10.9) \\
56.8(13.4)\end{array}$ & $\begin{array}{l}59(6.7) \\
56.9(10.4)\end{array}$ & $\begin{array}{l}>0.05 \\
>0.05\end{array}$ \\
\hline
\end{tabular}


The aortic clamping time did not differ between groups - 54 (12) min in Group 1 and 63 (33) $\mathrm{min}$ in Group 2 ( $p>0.05)$ (Table 1). However, duration of mechanical ventilation was significantly higher in Group 2 as compared to Group 1 ( $p=0.009$ ).

In the early postoperative period, 8 (33.3\%) patients in first group, needed support with cardiotonic drugs, all patients were extubated on the 1st day, 17 patients were transferred from the ICU department on the 1st day. In the second group, 9 (52.9\%) patients needed cardiotonic drugs support, 15 patients were extubated on the 1st day, transfer from the ICU to the department was mainly on the 2 nd and 3rd day.

Indicators of transthoracic echocardiography at admission and before discharge are presented in Table 2.

In the first group, there is a decrease in the anteroposterior size of the LA ( $p<0.05)$, an unreliable decrease in the end-diastolic and systolic dimensions of the left ventricle $(p>0.05)$, also a decrease in the end-diastolic volume of the left ventricle $(p>0.05)$ and a significant decrease in the end-systolic volume $(p<0.05)$ and a slight increase in the ejection fraction of the left ventricle $(p>0.05)$.

In the second group, there is a decrease in the anteroposterior size of the left atrium $(p<0.05)$, an unreliable decrease in the end-diastolic size ( $p>0.05$ ); the systolic size of the left ventricle has not changed. There was a significant decrease in the end-diastolic volume of the left ventricle $(p<0.05)$ and an unreliable decrease in the end-systolic volume $(p>0.05)$, the LV ejection fraction did not change.

A significant decrease in both end-diastolic and endsystolic volume was observed in patients with mitral valve lesions with a predominance of regurgitation in Group 1 ( $n=12$ ) before surgery EDV 134 (61) ml, after surgery 105 (51.3) $\mathrm{ml}, \mathrm{p}<0.05$, ESV before surgery 54.1 (23.6) $\mathrm{ml}$, after surgery 42.8 (22.4) $\mathrm{ml},(p<0.05)$, while in patients with a predominance of stenosis, the end-systolic volume did not significantly decrease (before surgery ESV 34.2 (14.7) $\mathrm{ml}$, after surgery 31.5 $(10.5 \mathrm{ml}), \mathrm{p}>0.05)$. In Group 2, in patients with a predominance of regurgitation, a significant decrease in the end-diastolic volume was obtained (before operation EDV 150 (58.2) ml, after surgery 133 (49.4) $\mathrm{ml}, \mathrm{p}<0.05)$, an unreliable decrease in the end-systolic size (ESV before surgery $65.8(41.4) \mathrm{ml}$, after surgery 61.0 (36.7) $\mathrm{ml}, \mathrm{p}>0.05$ ) and in patients with a predominance of stenosis, on the contrary, there is a slight increase in the end-systolic volume (before surgery ESV 27.8(7.0) $\mathrm{ml}$, after surgery 30.2 (4.9) $\mathrm{ml}$, $p>0.05$ ).

\section{Discussion}

Preliminary results of our study demonstrated reversal of LV remodeling in patients with preservation of chordopapillary structure of both leaflets of mitral valve, the better results (larger decrease in EDV) were obtained for patients with predominance of mitral valve regurgitation. Our patients' groups did not differ by intraoperative and postoperative variables except ventilation time which was higher in a group of preservation of only posterior leaflet $(p<0.05)$. This can be a random finding, due to small sample size and can be explained by prolonged ventilation of 2 patients with NYHA III class and normal LV function.

Valve-saving operations undoubtedly have advantages over mitral valve prosthetics; however, this issue remains controversial in rheumatic lesions, where gross valve changes require replacement. Despite numerous studies with the advantages of retaining subvalvular structures from both cusps during MVR, different surgeons have different points of view, and some consider it sufficient to preserve only the posterior cusp (13). When assessing LV remodeling, after MVR in the early and late postoperative periods, patients with a predominance of regurgitation, that is, having pronounced changes in LV geometry before surgery, are considered more indicative (14), which was confirmed in our study.

\section{Limitations of the study}

The main limitation of the study is its retrospective design and small sample size. Further studies on larger population are required.

\section{Conclusion}

This study shows the possibility of implanting the right size of the artificial heart valve, with rheumatic lesions of the mitral valve with the complete preservation of subvalvular structures. Preliminary results of the study indicate the best remodeling and optimization of the geometry of the left ventricle when assessing the nearest postoperative parameters in a group of patients with preservation of chordo-papillary structures from both leaflets, both the anterior and the posterior leaflets. Significant improvement in echocardiographic results is observed in patients with a predominance of regurgitation. It is advisable to evaluate a group of patients with a predominance of stenosis with a large number of patients.

Peer-review: External

Conflict of interest: None to declare

Authorship: D.B.T., M.K.D., E.D.S., I.A. A. are equally contributed the study and preparation of article

Acknowledgments and funding: None to declare 


\section{References}

1. Charles M.M., Marta P., Alessandro G., David Ch., Liliane M.K. Jerome B., Ellen M.D. Surgery for rheumatic mitral valve disease in sub-saharan African countries: why valve repair is still the best surgical option. Pan Afr Med J 2016; 24: 307.

2. Geldenhays A., Koshy J., Human P., Mtwale J.F. Rheumatic mitral repair versus replacement in a threshold country: the impact of commissural fusion. J Heart Valve Dis 2012; 21: 424-32.

3. van der Merwe J, Casselman F. Mitral valve replacement-current and future perspectives. doi.org/10.1177/1179065217719023.

4. Ozdemir AC, Emrecan B, Baltalarli A. Bileaflet versus posterior-leaflet-only preservation in mitral valve replacement. Tex Heart Inst J 2014; 41: 165-9.

5. Lillehei CW, Levy MJ, Bonnabeau RC. Mitral valve replacement with preservation of papillary muscles and chordae tendineae. J Thorac Cardiovasc Surg 1964; 47: 532.

6. Lafci G, Cagli K, Cicek OF, Korkmaz K, Turak O, Uzun $A$, et al. Papillary muscle repositioning as a subvalvular apparatus preservation technique in mitral stenosis patients with normal left ventricular systolic function. Tex Heart Inst J 2014; 41: 33-9.

7. Chen L, Chen B, Hao J, Wang X, Ma R, Cheng $W$, et al. Complete preservation of the mitral valve apparatus during mitral valve replacement for rheumatic mitral regurgitation in patients with an enlarged left ventricular chamber. Heart Surg Forum 2013; 16: E137-43.

8. Coutinho GF, Bihun V, Correia PE, Antunes PE, Antunes MJ. Preservation of the subvalvular apparatus during mitral valve replacement of rheumatic valves does not affect long-term survival. Eur J Cardiothorac Surg 2015; 48: 861-7.
9. Yilong Guo, Shuwu He, Tianguang Wang, Comparison of modified total leaflet preservation, posterior leaflet preservation, and no leaflet preservation techniques in mitral valve replacement a retrospective study. J Cardiothorac Surg 2019; 14: 102.

10.Lang RM, Badano LP, Mor-Avi V, Afilalo J, Armstrong A, Ernande L, et al. Recommendations for cardiac chamber

quantification by echocardiography in adults: an update from the American Society of Echocardiography and the

European Association of Cardiovascular Imaging. J Am Soc Echocardiogr 2015; 28: 1-39.

11.Baumgartner $\mathrm{H}$, Hung J, Bermejo J, Chambers JB, Evangelista A, Griffin BP, et al. Echocardiographic assessment of valve stenosis: EAE/ASE Recommendations for Clinical Practice. J Am Soc Echocardiogr 2009; 22: 1-23.

12. Lancellotti P, Tribouilloy C, Hagendorff A, Popescu $B A$, Edvardsen T, Pierard PA, et al. Recommendations for the echocardiographic assessment of native valvular regurgitation: an executive summary from European Association of Cardiovascular Imaging. Eur Heart J Cardiovasc Imaging 201; 14: 611-44.

13. Chowdhury UK, Kumar AS, Airan B, Mittal D, Subramaniam G, Prakash R, et al. Mitral valve replacement with and without chordal preservation in a rheumatic population: serial echocardiographic assessment of LV size and function. Ann Thorac Surg 2005; 79: $1926-33$.

14. Timala RB, Joshi D, Aryal M, Bhandari K, Singh $Y$, Sharma J. Effects of subvalvular apparatus preservation in mitral valve replacement among rheumatic patients: early and mid-term follow up. J Inst Med 2016, 38: 2-3. 